Int. J. Electrochem. Sci., 15 (2020) 12569 - 12577

International Journal of

ELECTROCHEMICAL

SCIENCE

WWW.electrochemsci.org

\title{
Hierarchical Assembly and Enhanced Lithium Storage Properties of 3D $\mathrm{SnO}_{2} / \mathrm{PC}$ Hybrids
}

\author{
Yuzhen Sun, Yumei Chen, Xiaowei Yang ${ }^{*}$ Yuxiang Zuo, Zhiyuan Zhao* and Bing Huang \\ Institute of New Energy on Chemical Storage and Power Sources, College of Applied Chemistry and \\ Environmental Engineering, Yancheng Teachers University, Jiangsu, Yancheng 224000, China. \\ *E-mail:xiaoweiyang215@126.com, zhiyuan.zhao@ rcclab.com
}

doi: $10.20964 / 2020.12 .06$

Received: 27 July 2020 / Accepted: 15 September 2020 / Published: 10 October 2020

Ultrasmall $\mathrm{SnO}_{2}$ nanoparticles ( $3 \mathrm{~nm}$ in diameter) confined in three dimensional hierarchical porous carbon $\left(3 \mathrm{D} \mathrm{SnO}_{2} / \mathrm{PC}\right.$ ) were successfully prepared using a simple method in this work. The 3D $\mathrm{SnO}_{2} / \mathrm{PC}$ has almost monodispersion of the $\mathrm{SnO}_{2}$ nanoparticles with $73 \mathrm{wt} \%$ load. The $3 \mathrm{D} \mathrm{SnO}_{2} / \mathrm{PC}$ exhibits excellent performance with high rate capability and significant cycle stability. At $0.1 \mathrm{~A} / \mathrm{g}$ in the 100th cycle, the reversible specific capacity is $1374 \mathrm{mAh} / \mathrm{g}$. These outstanding characteristics are desirable and make 3D $\mathrm{SnO}_{2} / \mathrm{PC}$ a promising anode material for LIBs.

Keywords: 3D porous carbon; Tin dioxide; Anode; Lithium ion battery

\section{$\underline{\text { FULL TEXT }}$}

(C) 2020 The Authors. Published by ESG (www.electrochemsci.org). This article is an open access article distributed under the terms and conditions of the Creative Commons Attribution license (http://creativecommons.org/licenses/by/4.0/). 